Article

\title{
Investigating How the Rents of Small Urban Houses are Determined: Using Spatial Hedonic Modeling for Urban Residential Housing in Seoul
}

\author{
Jaewoong Won ${ }^{1}$ and Jae-Su Lee ${ }^{2, *}$ \\ 1 Department of Real Estate, Graduate School of Tourism, Kyung Hee University, Seoul 02447, Korea; \\ jwon@khu.ac.kr \\ 2 Department of Real Estate, College of Social Sciences, Kangwon National University, \\ Gangwon-do 24341, Korea \\ * Correspondence: jslee25@kangwon.ac.kr; Tel.: +82-33-250-6831
}

Received: 16 November 2017; Accepted: 18 December 2017; Published: 23 December 2017

\begin{abstract}
The Seoul metropolitan government has launched the Urban Residential Housing (URH) program to address the shortage of small urban houses, and enhance residential stability for the increasing number of one- and two-person households in Seoul, Korea. While studies have examined the price premium of locational and neighborhood environmental features for houses in general, little is known about how and to what extent these features influence the rents of small urban houses. We estimate and compare conventional and spatial hedonic price models (HPMs) to examine the effects of those features on the monthly rents of URH units, while using geographic information system techniques to measure the variables. We found that the spatial HPM outperforms the conventional HPM in terms of goodness of fit measures. All of the locational features, and most of the variables with respect to the neighborhood environment, had a significant impact on rents. Rent tended to be lower in areas adjacent to a university, suggesting that it is a good place for one and two-person households to enhance residential affordability. However, access to parks does not appear to be important for residents. We conclude that the people who live in small urban houses are inclined to place a premium on rents in different ways.
\end{abstract}

Keywords: small urban house; Urban Residential Housing; house price; hedonic price model; spatial lag model; spatial error model; one-person household; neighborhood environment

\section{Introduction}

The Seoul metropolitan area (SMA) is one of the most densely populated capitals in the world. Around 10 million people and 3.78 million households reside in the SMA, which has a land area of 605 square kilometers [1]. Over the past several decades, the SMA's population and household structures have changed significantly. The proportion of the population over 65 was $3.42 \%$ in 1990 , but this percentage increased to $12.31 \%$ by 2015 [1,2]. The relative proportion of children has consistently decreased in comparison with the growing elderly population due to the SMA's diminishing birth rate. The overall population in the SMA has also been on the decline.

While the SMA's population has been declining for several decades, the number of households has been increasing, mainly because of the growing number of one and two-person households. The proportion of one and two-person households grew from $20.9 \%$ in 1990 to $54.7 \%$ in 2015 . However, the housing supply has not kept pace with the rapid changes in the SMA's household structure. Concerns about this imbalance in housing supply have led policymakers to provide incentives for increasing the number of new small urban houses. Consequently, the Urban Residential Housing (URH) program was introduced in the Housing Act in May 2009. It aims to address the shortage of small urban houses, 
and enhance residential stability for one and two-person households in the SMA. A variety of financial supports and institutional incentives have been offered to developers.

As a result, the number of URH units in urban areas has increased rapidly. The number of units approved for development totaled 8379 at the end of 2010 . This number increased to 176,410 by the end of 2016, which represented a 20-fold increase over six years. This increase contributed to relieving the shortage of small urban houses; however, it has been argued that the high rents charged for these houses, relative to residents' income levels, threaten residential stability and affordability [3]. It should also be noted that one and two-person households are assumed to have housing demands that are different from the demands of other households. It is claimed that these residents tend to prefer living in small houses with better access to public transit, jobs, and recreational amenities, while giving a low priority to green spaces and the quality of school districts [3-5].

This study examines how and to what extent locational and neighborhood environmental features influence the monthly rents of URH in the SMA. Most of the research to date has paid attention to the effects of locational and neighborhood environmental features on the property values of houses in general. However, there is not enough evidence to verify whether and how they affect the monthly rents of small urban dwellings. To address this issue, this research incorporates three different data sets. A structured questionnaire survey was conducted for 244 residents between 10 December 2012 and 11 January 2013. Census data in relation to population, households, and businesses as of 2010, and spatial data as of 2012, were collected. Using geographic information system (GIS) techniques, these data sets are combined, and various spatial attributes are analyzed. The results of a conventional hedonic price model (HPM) and an advanced HPM with spatial adjustments are then compared.

The following section of this paper, Section 2, provides a review of the relevant research regarding the effects of structural, locational, and neighborhood environmental characteristics on house prices. Section 3 elaborates on a methodology in which spatial HPMs are specified, and the data and variable measures employed in the study are explained. The URH development pattern and empirical models are displayed and interpreted in Section 4 . The final section, Section 5, offers concluding remarks.

\section{Literature on Quantitative Valuation of House Prices}

A number of studies have examined how a variety of factors determine residential property values. In hedonic price modeling, these factors commonly include structural features, locational characteristics, and neighborhood environmental attributes. A brief review of the relevant research and the knowledge gaps pertinent to this inquiry are presented in this section.

First, it should be noted that all of the relevant studies confirm that structural features affect house prices. Physical factors including floor areas, a building's age, and the number of stories, bedrooms, and bathrooms, have proven to be significant to varying degrees [6-12]. Jun and Kim [12], for instance, found that both floor areas and the number of stories have positive impacts on the monthly rent charged for apartments; the age of a dwelling, however, influences rent negatively.

Even though physical and structural features have statistically significant effects on housing values, house prices are also influenced by the locations of dwelling units. One notion that defines the field of real estate is "location, location, location", which infers that there is a significant relationship between locational characteristics and housing values $[6,7,13]$. Locational factors considered in property valuation studies to date are closely related to accessibility measures. Accessibility to major business districts, transportation infrastructure such as major roads, bus stops, and subway and railway stations, and various facilities including schools, shopping centers, and churches were examined [14-16]. The relationship between housing prices and location in a particular zone such as a commercial zone has also been explored [12].

Tse [17] developed a stochastic model dealing with the spatial autocorrelation bias in the hedonic model. Only transit accessibility was considered as a location variable in the study, and it was found to have a significant positive impact on house prices. Cohen and Coughlin [6] compared a variety 
of spatial hedonic models to examine the effects of airport noise and proximity on house prices in Atlanta, and found that these variables played a significant role in explaining implicit housing values.

Hui et al. [7] paid attention to location-specific housing factors in Hong Kong. Travel time to major business districts, access to public transit, and the number of schools were considered using spatial hedonic models. Both public transit and education factors were found to be positive; travel time, on the other hand, was found to have a negative relationship with house prices. Lee and Li [8] explored the impacts of different types of detention basins on residential property values. Various accessibility measures were employed in these models, including distance to adjacent principal roads, highways, commercial districts, and the basins.

$\mathrm{Ki}$ and Jayantha [18] examined the impacts of an urban redevelopment project on house prices in the surrounding areas, while considering the project's various stages. They found that the prices of adjacent residential properties increased during the project, with the greatest impacts occurring on houses closer to the area. Jayantha et al. [10] identified different groups of location and neighborhood variables, and compared them with previous research on residential property valuations. The effects of two locational factors on housing values were explored: distance to a transport center, and an interaction term comprised of the distance and a dummy for a post-announcement state of a transit improvement project. Both variables were negatively correlated with house prices, implying that the announcement of the project had a positive impact on house prices. Jun and Kim [12] provide an overview of a number of relevant studies regarding the effects of greenbelt proximity on housing rents. Many locational factors are incorporated into their spatial hedonic models such as distance to subway stations, highway interchanges, schools, central business districts (CBDs), employment sub-centers, and employment density. The study showed that the houses that were located near services and facilities had premium values. Employment density was also positively correlated with housing prices.

In the hedonic pricing studies, housing values are regressed on structural features and locational characteristics, as well as neighborhood environmental attributes. More recently, academics have investigated the effects of these attributes. They encompass access to green and open spaces, access to amenities such as parks, playgrounds, sea views, watercourses, and landscapes, and environmental conditions such as noise and air quality levels [6-12].

Most studies found that indicators that measured access to green and open spaces correlated ready access to these spaces with a significant premium on housing values. Lee and Li [8], Gibbons et al. [16], and Bolitzer and Netusil [19] introduced variables based on the distance to parks and open spaces in their hedonic models, and suggested that proximity to green and open spaces had a significant impact on residential property values.

There is also significant evidence that access to various amenities is positively associated with housing values in the community [14,16,20]. Jun and Kim [12], on the other hand, found that people were less willing to pay rent for apartments that were closer to the greenbelt in the SMA. They suggested that this could be due to the downtown area's spatial structure and vitality. In Hong Kong, for example, the value of a greenbelt is statistically insignificant [7]. In addition, access to different types of facilities could impact house prices in different ways. Lee and Li [8] compared the effects of different types of detention basins on residential property values. They argued that living closer to a multi-use detention basin positively affected residential property values; however, proximity to a single-use detention basin had a negative effect on house prices. This implies that the factors that create a real estate premium should often be considered in different contexts.

It is well documented that a nice view of water and a landscape contributes to a high real estate valuation. Tse [17] and Hui et al. [7] found that house prices in Hong Kong increased when the residents could clearly enjoy a view of the sea. Jayantha et al. [10] asserted that a garden view and a sea view were positively correlated with increases in housing sale prices. Chen and Li [11] also identified a positive impact of stream views on property values, although in this case, a greater distance from a stream had a positive effect, due to water pollution. Kuethe [21] investigated the effect of land-use diversity and fragmentation on housing values by employing spatial lag and spatial error models. They 
found that land-use fragmentation had a positive impact on house prices, while land-use diversity had no significant effect.

It is widely argued that poor environmental quality influences real estate values in a negative way, and thus reduces housing value premiums. Hui et al. [7] examined how a property's noise levels and air pollution affected residential property values in Hong Kong. They found that an air pollution had a negative effect on house prices; however, there was no evidence of significant impacts from ambient noise levels. This result is not consistent with earlier studies, which maintained that noise had adverse impacts on housing values [6,22,23].

In addition, some studies also found that neighborhood socio-demographic characteristics play a significant role in determining house prices. Visser et al. [15] considered some socio-demographic variables, including population density and the proportion of single-family dwellings in a neighborhood. It was found that they had negative impacts on house prices, which was possibly due to congestion and insecurity. Gibbons et al. [16] incorporated population density into the HPMs, and found that it was not significant for house prices in England. However, the study showed the significant impact of population density on house prices in some regions.

Most studies have enhanced our understanding of how locational features and neighborhood environmental attributes impact house prices. However, how small urban houses are influenced by these factors has not yet been thoroughly analyzed. This area of study is worthy of notice by academia and practitioners, because both one- and two-person households may have a different pattern of housing demands. Some researchers have speculated that they are inclined to place a higher premium on small houses with better access to transit, employment, and amenities; however, access to schools for children and nature may be less attractive to them [3-5].

Some studies have examined how locational features and neighborhood environmental attributes affect house prices and the rental values of small urban house in Korea. Kim [4] stated that the sale prices of URH were influenced by various structural, locational, and community variables. This study showed that the proportion of one-person households, distance to subway stations, population size, and the presence of an urban center in a neighborhood all had significant impacts on housing values. Park [24] revealed that both job opportunities and access to public facilities had stronger effects on house prices than other physical and neighborhood environmental attributes. It is also argued that the magnitude of a variable's importance could vary according to the hierarchical structure of an urban center; for example, in Seoul, there is an urban core, sub-core, and major center. This implies that spatial characteristics should be properly considered in drafting a housing policy for expanding the housing supply and enhancing the quality of the residential environment. Lee et al. [5] investigated what factors had significant impacts on the rents of URH in the SMA, using local rent quantile regressions. They concluded that rents seemed to be affected by both physical factors and locational features, and suggested that housing policies should consider different magnitudes of variables according to housing sub-markets in order to keep them more affordable.

\section{Methodology}

\subsection{Hedonic Price Model}

In real estate valuation research, the HPM assumes that a house is composed of a variety of independent characteristics. Our preference for any house is presumed to be determined by its characteristics. This implies that we acquire not only a residential structure when we purchase a house in a community, but also locational and environmental amenities [7,8,25]. In this sense, a house price is made up of the specific values of a bundle of characteristics, which can be classified into four heterogeneous dimensions, that is, structural and physical attributes, spatial and locational features, neighborhood environmental qualities, and socio-demographic characteristics [8,25-27]. The functional form of a HPM can be denoted as follows:

$$
H P=f\left(x_{1}, x_{2}, \cdots, x_{m}\right)=f\left(X_{S}, X_{L}, X_{E}, X_{D}\right),
$$


where $H P$ is the house price, and $x_{1}, x_{2}, \cdots, x_{m}$ are heterogeneous characteristics of the house, which are supposed to be categorized into four groups, including structural attributes $\left(X_{S}\right)$, locational features $\left(X_{L}\right)$, neighborhood environmental qualities $\left(X_{E}\right)$, and socio-demographic characteristics $\left(X_{D}\right)$.

In the equation, structural attributes include the residential area, building age, number of rooms, and number of parking lots. Locational features include the distance to major business districts, transit accessibility, and roadway accessibility. Neighborhood environmental qualities include the number of public amenities near the house, noise levels, and the distance to parks. Also, socio-demographic characteristics encompass population density, median income, and age composition. The functional form of HPM in consideration of the characteristics of the house can be represented as follows:

$$
H P=\beta_{0}+\beta_{S} X_{S}+\beta_{L} X_{L}+\beta_{E} X_{E}+\beta_{D} X_{D}+\varepsilon,
$$

where $H P$ is a $(n \times 1)$ vector of house prices; $X_{S}$ is a $(n \times i)$ matrix of structural attributes; $\beta_{S}$ is the estimated coefficient vector for the variables implying the effects of structural attributes on house prices; $X_{L}$ is a $(n \times j)$ matrix of locational features; $\beta_{L}$ is the estimated coefficient vector for the factors representing the effects of locational features on house prices; $X_{E}$ is a $(n \times k)$ matrix of neighborhood environmental qualities; $\beta_{E}$ is the estimated coefficient vector for the variables indicating the effects of environmental qualities on house prices; $X_{D}$ is a $(n \times m)$ matrix of socio-demographic characteristics; $\beta_{D}$ is the estimated coefficient vector for the variables implying the effects of socio-demographic characteristics on house prices; $\beta_{0}$ is a constant; and $\varepsilon$ is a $(n \times 1)$ vector of error term assumed to be normally distributed with a zero mean and constant variance.

Substantial progress has been made over decades in specifying empirical HPMs for examining the impacts of both the locational and neighborhood environmental features described above. Krause and Bitter [13] addressed methodological issues surrounding advanced spatial models in real estate valuation research. Two different forms of specifying spatial HPMs were introduced in the study: the spatial lag model and the spatial error model $[28,29]$. The spatial lag or spatial autoregressive (SAR) model can be represented as:

$$
\begin{gathered}
y=\rho W y+X \beta+\varepsilon, \text { or } \\
y=(I-\rho W)^{-1} X \beta+(I-\rho W)^{-1} \varepsilon,
\end{gathered}
$$

where $y$ is a $(n \times 1)$ vector of house prices; $\rho$ indicates a spatial autoregressive parameter; $W y$ is a spatially lagged price variable with a $(n \times n)$ spatial weight matrix $W ; X$ is a $(n \times m)$ vector of explanatory variables of interest; $\beta$ is a $(m \times 1)$ vector of coefficient estimates; and $\varepsilon$ is a $(n \times 1)$ vector of error term.

It is worth noting that the coefficient estimates computed with the OLS regression method would be biased without considering a spatial lag in regard to house prices. The spatial autoregressive coefficient $(\rho)$ confirms the hypothesis that there exists a spatial autocorrelation problem in house prices $[28,30,31]$.

In addition, another form of spatial HPM, the spatial error model (SEM), can also be denoted:

$$
\begin{gathered}
y=X \beta+\varepsilon, \text { where } \varepsilon=\lambda W \varepsilon+u=(I-\lambda W)^{-1} u, \text { or } \\
y=X \beta+(I-\lambda W)^{-1} u=\lambda W y+X \beta+\lambda W X \beta+u,
\end{gathered}
$$

where $y$ is a $(n \times 1)$ vector of house prices; $X$ is a $(n \times m)$ vector of independent variables; $\beta$ is a $(m \times 1)$ vector of coefficient estimates; $\varepsilon$ is a $(n \times 1)$ vector of error term; $W \varepsilon$ is a spatially lagged error term with a $(n \times n)$ weight matrix $W ; \lambda$ points to a spatial autoregressive parameter for the error lag; and $u$ is a $(n \times 1)$ vector of residuals with a constant variance.

It is also necessary to mention that the coefficient estimates computed with a conventional ordinal least squares (OLS) regression method would not be biased; however, they would be inefficient without considering a spatial error term in the modeling process [28]. Anselin [29] proposed a decision-making process for selecting a more appropriate spatial regression model. 


\subsection{Data and Measurement}

\subsubsection{Study Area}

There are over 10 million people living in the Seoul metropolitan area (SMA), which covers about 605 square kilometers. As the capital of the Republic of Korea, the SMA is composed of 25 autonomous boroughs or local governments. While the SMA forms the capital region together with the adjoining Incheon metropolitan city and Gyeonggi province, its sphere of daily commuting and living activities goes beyond the administrative boundary.

The SMA has experienced incremental changes in its population and household structures. While the population has slowly declined over several decades, the number of households has grown considerably, as shown in Table 1 . This is mainly attributed to a rapid growth in the number of one and two-person households in the SMA. Table 1 indicates that the share of both one and two-person households has substantially increased from 20.9\% in 1990, to 54.7\% in 2015. However, the housing supply rate as the ratio of housing units to total households was only $96.0 \%$ in 2015 [1]. This mismatch has given rise to a high demand for small housing units.

Table 1. Changes of household structure between 1990 and 2015 in the Seoul metropolitan area (SMA).

\begin{tabular}{ccccc}
\hline Year & No. of Households * & $\begin{array}{c}\text { Avg. No. of People } \\
\text { per Household }\end{array}$ & $\begin{array}{c}\text { One-Person } \\
\text { Household (\%) }\end{array}$ & $\begin{array}{c}\text { One and Two-Person } \\
\text { Households (\%) }\end{array}$ \\
\hline 1990 & $2,814,845$ & 3.77 & 9.1 & 20.9 \\
1995 & $2,965,794$ & 3.45 & 12.9 & 27.3 \\
2000 & $3,085,936$ & 3.19 & 16.3 & 33.3 \\
2005 & $3,309,890$ & 2.95 & 20.4 & 40.7 \\
2010 & $3,504,297$ & 2.75 & 24.4 & 46.7 \\
2015 & $3,784,705$ & 2.50 & 30.1 & 54.7 \\
\hline
\end{tabular}

* Household indicates a common household comprised of family members including more than a Korean, while neither foreign households nor group households without family members are considered. Source: [1,2,32-35].

This study focuses on the SMA, as illustrated in Figure 1. This map also depicts URH development locations between 2009-2012. It suggests that URH has been built over the entire metropolitan area, with the exception of waterfront areas, natural parks, and preservation zones. In reality, URH has been principally developed in the metropolitan area's general residential zone.

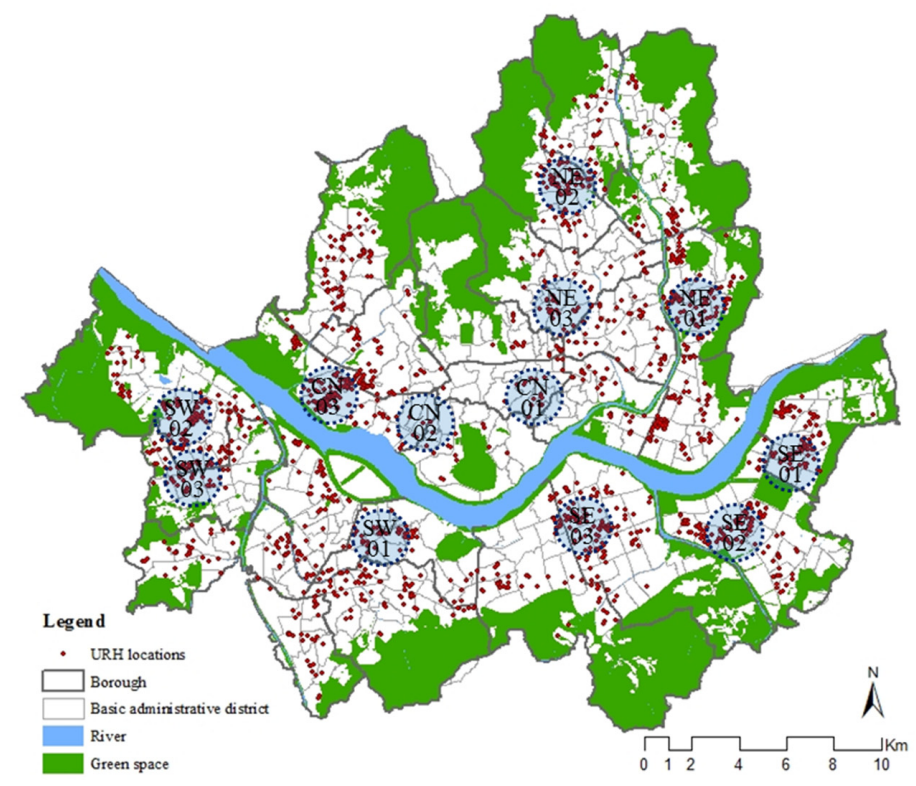

Figure 1. Map of study area, Urban Residential Housing (URH) locations and survey sampling areas. Note: The survey sampling areas indicated by the circles are presented in Table 2. 
Table 2. Distribution of survey samples by sub-regions, housing types, and locations.

\begin{tabular}{|c|c|c|c|c|c|c|}
\hline \multirow[b]{2}{*}{$\begin{array}{l}\text { Housing } \\
\text { Type }\end{array}$} & \multirow[b]{2}{*}{ Location } & \multicolumn{4}{|c|}{ Sub-Region } & \multirow[b]{2}{*}{ Total } \\
\hline & & $\begin{array}{c}\text { Core and } \\
\text { Northwestern (CN) }\end{array}$ & $\begin{array}{l}\text { Northeastern } \\
\text { (NE) }\end{array}$ & $\begin{array}{c}\text { Southwestern } \\
\text { (SW) }\end{array}$ & $\begin{array}{l}\text { Southeastern } \\
\text { (SE) }\end{array}$ & \\
\hline \multirow{2}{*}{ Complex } & TOD & $0(0.0 \%)$ & $5(2.0 \%)$ & $5(2.0 \%)$ & $0(0.0 \%)$ & $10(4.1 \%)$ \\
\hline & Non-TOD & $0(0.0 \%)$ & $15(6.1 \%)$ & $20(8.2 \%)$ & $0(0.0 \%)$ & $35(14.3 \%)$ \\
\hline \multirow{2}{*}{ Studio } & TOD & $20(8.2 \%)$ & $45(18.4 \%)$ & $33(13.5 \%)$ & 29 (11.9\%) & $127(52.0 \%)$ \\
\hline & Non-TOD & $20(8.2 \%)$ & $16(6.6 \%)$ & $21(8.6 \%)$ & $15(6.1 \%)$ & $72(29.5 \%)$ \\
\hline \multicolumn{2}{|c|}{ Total } & $40(16.4 \%)$ & $81(33.2 \%)$ & $79(32.4 \%)$ & $44(18.0 \%)$ & $244(100.0 \%)$ \\
\hline
\end{tabular}

There have been 11,999 URH buildings and 176,410 housing units approved for development in the SMA since the URH was introduced in 2009. The number of buildings and units increased consistently until 2012, mainly due to institutional and financial incentives. Development numbers were stagnant between 2013-2014, after which there was a sharp growth that continued until the middle of 2015. Since then, development numbers have again been decreasing, as illustrated in Figure 2.

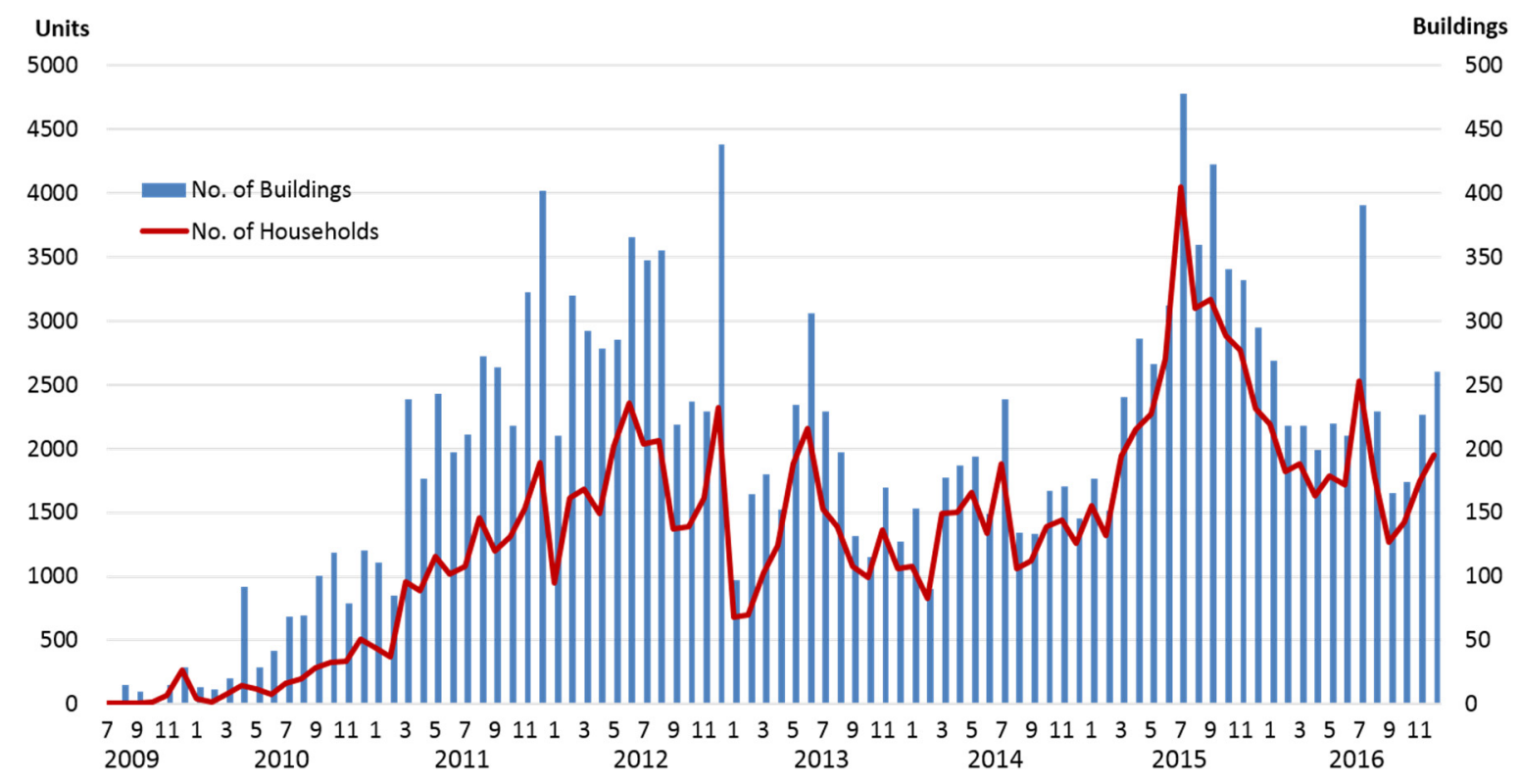

Figure 2. The number of URH buildings and households permitted between 2009-2016 in the SMA.

Most of the housing units approved for development until the end of 2016 are small, with $69.3 \%$ $(122,165$ units) of the residential units being less than 40 square meters in size, as presented in Figure 3. In particular, housing units that are less than 30 square meters account for 55.1\% (97,024 units) of all of the URH units. Almost all of the small units are classified as studio apartments. The development trends of small units that are less than 30 square meters in size, and medium units that are more than 30 square meters in size, are significantly different, as shown in Figure 4. Between 2009-2012, small URH units outnumbered the medium units; however, the situation reversed in 2013. 


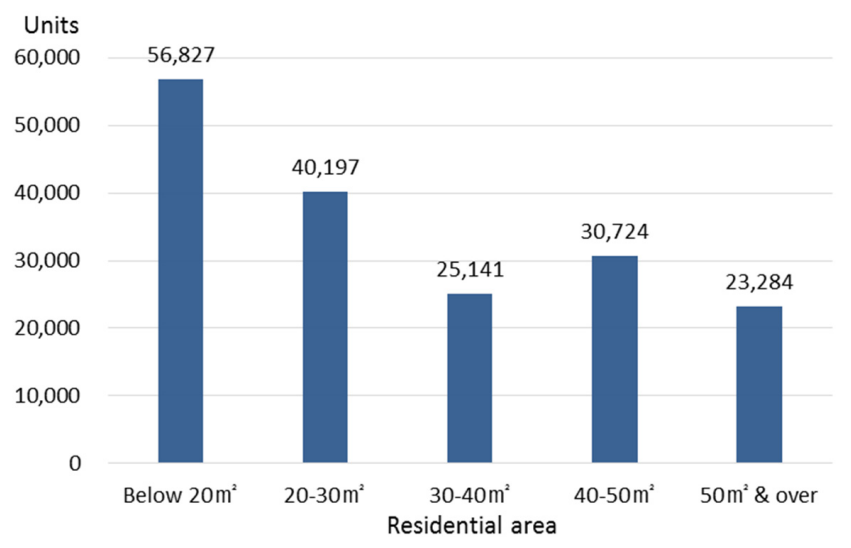

Figure 3. The number of housing units permitted in the SMA by residential area.

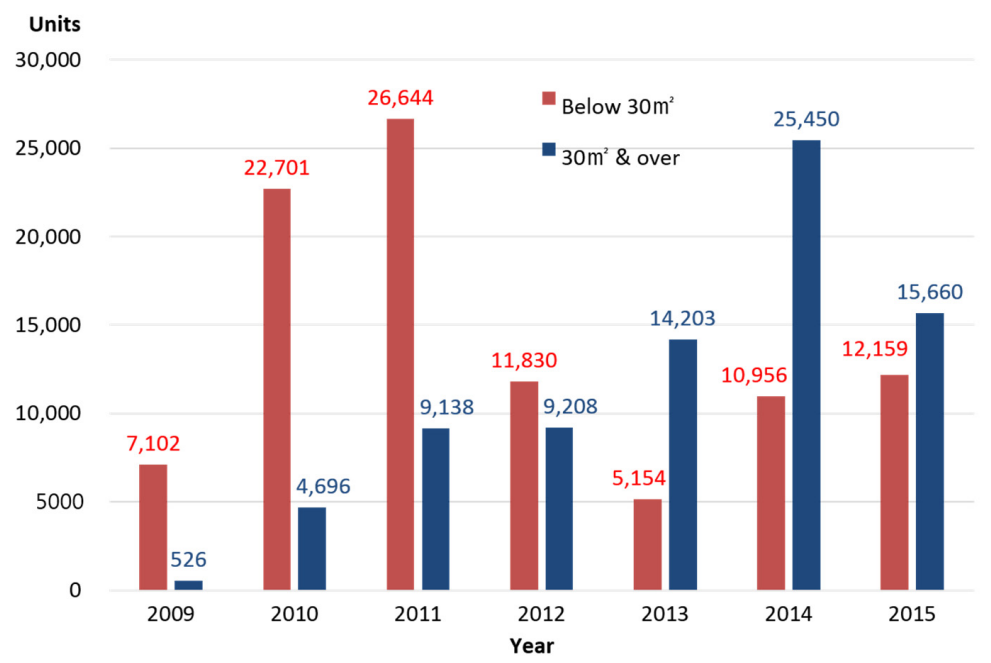

Figure 4. Comparing the number of small housing units with others permitted in the SMA.

\subsubsection{Data and Variable Measurement}

Three different data sources are incorporated into this study: survey data, census data, and GIS data. Residents were surveyed to collect information regarding living conditions, satisfaction levels, and the socioeconomic status of respondents. The survey was designed and conducted in cooperation with a survey company. On-site individual interviews were conducted using a structured survey questionnaire between 10 December 2012 and 11 January 2013. The questionnaire asked questions about living conditions such as location area and type; housing costs, including monthly rents, maintenance costs, and affordability; satisfaction with the indoor and outdoor residential environment; and respondents' socioeconomic status.

Both the sampling method and survey locations were carefully designed, because it was quite difficult to carry out individual interviews in which almost all of the small apartment buildings were secured with an individual access system and no management office. The residents of most one and two-person households also did not stay in their residences during the daytime. The sampling population was composed of 1173 URH buildings, and 25,937 housing units that had been approved for use by the end of 2012. A stratified random sampling method was applied, as presented in Table 2, in consideration of the five sub-regions within the SMA; housing types, such as studio and complex apartments; and locational traits, such as a transit-oriented district (TOD). A TOD is defined as being within a 500-m radius of subway stations. Finally, 12 survey sites were selected in which three locations for each sub-region were assigned, as shown in Figure 1. 
Census data were collected for measuring population density, the proportion of young single households, and the number of businesses. In addition, spatial information was gathered to efficiently calculate various accessibility measures and locational features using geographic information technology. Quantitative spatial measures included access to transit, colleges, parks, and public amenities.

Table 3 summarizes the attributes, definitions, and data sources of the study's dependent and independent variables. The dependent variable was monthly rent, which was first measured with the Korean won currency (KRW). In this study, we converted the KRW to the US dollar (USD) with $1260 \mathrm{KRW} / \mathrm{USD}$, based on the exchange rate at the end of 2012. The log-transformed value was used for the dependent variable. Explanatory variables were grouped into four categories based on the studies of hedonic prices: housing structure, spatial and locational features, neighborhood environmental qualities, and socio-demographic attributes. Of the 300 survey respondents, only 244 households living in rented houses were considered in the analysis.

Table 3. Attributes, definitions, and data sources of variables.

\begin{tabular}{|c|c|c|c|c|}
\hline \multicolumn{2}{|c|}{ Variable } & \multirow{2}{*}{$\begin{array}{l}\text { Attribute } \\
\text { Monthly rent } \\
\text { (USD) }\end{array}$} & \multirow{2}{*}{$\begin{array}{c}\text { Definition } \\
\text { Monthly rent of the housing in USD } \\
\text { transformed in natural logarithm }\end{array}$} & \multirow{2}{*}{$\begin{array}{c}\text { Data Source } \\
\text { Survey data, } 2012\end{array}$} \\
\hline Dependent variable & LN_RENT & & & \\
\hline \multirow{2}{*}{ Housing structures } & LN_AREA_RE & Residential area & $\begin{array}{l}\text { Total heated area in } \\
\text { residential property }\left(\mathrm{m}^{2}\right)\end{array}$ & \multirow{2}{*}{ Survey data, 2012} \\
\hline & LN_PARKING & No. of parking lots & $\begin{array}{l}\text { Number of parking lots in the property in } \\
\text { natural logarithm }\end{array}$ & \\
\hline \multirow{4}{*}{$\begin{array}{l}\text { Spatial and } \\
\text { locational features }\end{array}$} & DIS_CBD & Distance to CBD & $\begin{array}{l}\text { Network distance to the nearest central } \\
\text { business district (CBD) among the three } \\
\text { CBDs in Seoul }(\mathrm{km})\end{array}$ & \multirow{4}{*}{$\begin{array}{l}\text { Korea National Spatial } \\
\text { Data Infrastructure } \\
\text { (KNSDI) Portal, } 2012 \\
\text { (http://nsdi.go.kr) }\end{array}$} \\
\hline & DIS_CBD2 & $\begin{array}{l}\text { Square of distance } \\
\text { to CBD }\end{array}$ & $\begin{array}{l}\text { Square of distance to the nearest CBD } \\
\text { among the three CBDs in Seoul }(\mathrm{km})\end{array}$ & \\
\hline & SUB_PASS & $\begin{array}{c}\text { Subway } \\
\text { accessibility }\end{array}$ & $\begin{array}{l}1 \text { if the estate can be included in the } \\
\text { transit-oriented district, } 0 \text { otherwise }\end{array}$ & \\
\hline & D_UNIV & $\begin{array}{l}\text { Distance to } \\
\text { university }\end{array}$ & $\begin{array}{l}\text { Network distance to the boundary of the } \\
\text { nearest university from the property }(\mathrm{km})\end{array}$ & \\
\hline \multirow{2}{*}{$\begin{array}{l}\text { Neighborhood } \\
\text { environmental } \\
\text { attributes }\end{array}$} & AMENITY & $\begin{array}{l}\text { No. of public } \\
\text { amenities }\end{array}$ & $\begin{array}{l}\text { Number of public amenities, including } \\
\text { public culture and recreational centers } \\
\text { within a one-kilometer radius from the } \\
\text { centroid of the subject property }\end{array}$ & \multirow{2}{*}{$\begin{array}{l}\text { Korean Statistical } \\
\text { Information Service, } \\
\text { Statistics Korea, 2010 } \\
\text { (http:/ / kosis.kr) }\end{array}$} \\
\hline & D_PARK & Distance to park & $\begin{array}{l}\text { Network distance to the boundary of the } \\
\text { nearest park from the property }(\mathrm{m})\end{array}$ & \\
\hline \multirow{2}{*}{$\begin{array}{l}\text { Socio-demographic } \\
\text { factors }\end{array}$} & R_YG1HH & $\begin{array}{l}\text { Proportion of } \\
\text { young single } \\
\text { household }\end{array}$ & $\begin{array}{l}\text { Proportion of single households with } \\
\text { residents in their } 20 \text { s and } 30 \text { s to total } \\
\text { households (\%) }\end{array}$ & \multirow{2}{*}{$\begin{array}{l}\text { Seoul Statistics, } 2012 \\
\text { (http:// stat.seoul.go.kr); } \\
\text { KNSDI Portal, 2012 } \\
\text { (http://nsdi.go.kr) }\end{array}$} \\
\hline & POP_DEN & Population density & $\begin{array}{l}\text { Total population density divided by } \\
\text { urbanized area (=no./ha) }\end{array}$ & \\
\hline
\end{tabular}

The first explanatory variables are based on housing structures, and included residential areas and the number of parking lots. Some explanatory variables representing housing structures were measured first. These included the number of bedrooms and the building's age. They are not considered in the final analysis, however, mainly due to the characteristics of small urban residential units, although they have proven significant in the literature.

A second group of explanatory variables were based on spatial and locational features, which encompassed the distance to the central business district (CBD), subway accessibility, and the distance to a university. Distance to the CBD represented how far the residence was from the nearest CBD to the residential property, which was measured in the network distance using GIS techniques. The distance to CBD variable and its squared term were considered in the HPM for the non-linear association with rent. They implied that the rents decrease as the distance increases; however, this effect fades away past a certain extent. Subway accessibility indicates whether a house is located in the TOD or not. In addition, the distance to university was a measure of education accessibility, which was 
obtained by computing the network distance to the boundary of the adjacent university using GIS techniques. Distances to elementary, middle, and high schools were not considered, because most of the respondents did not have children. A number of variables were also created, such as the distance to the nearest major road, the number of bus stops, and the number of business and commercial zones, but they were excluded in the final model due to the multicollinearity problem and insignificant correlations with the rents.

The third group of explanatory variables was comprised of a neighborhood's environmental attributes, which included the number of public amenities and the network distance to parks. The number of public amenities counted the number of public cultural centers and recreational centers within a one-kilometer radius of the property's center. The network distance to the nearest park represented access to natural assets.

The last group of explanatory variables consisted of socio-demographic characteristics, which included population density and the proportion of young single households. The population density was measured as the number of people residing in the smallest administrative district, divided by the urbanized area in which the green spaces were discounted. The proportion of young single household indicated the likely demand for small urban houses, and was measured as the ratio of one-person households that had members in their 20s and 30s to the total number of households in the smallest administrative area. Descriptive statistics for both the dependent and explanatory variables are presented in Table 4.

Table 4. Descriptive statistics of the dependent and explanatory variables.

\begin{tabular}{|c|c|c|c|c|c|c|}
\hline \multicolumn{2}{|l|}{ Variable } & \multirow{2}{*}{$\begin{array}{c}\text { Attribute } \\
\text { Monthly rent (USD) }\end{array}$} & \multirow{2}{*}{$\begin{array}{l}\text { Mean } \\
6.31\end{array}$} & \multirow{2}{*}{$\begin{array}{l}\text { Std. } \\
\text { Dev. }\end{array}$} & \multirow{2}{*}{$\begin{array}{l}\text { Min. } \\
5.62\end{array}$} & \multirow{2}{*}{$\begin{array}{l}\text { Max. } \\
7.11\end{array}$} \\
\hline Dependent variable & LN_RENT & & & & & \\
\hline \multirow{2}{*}{ Housing structures } & LN_AREA_RE & Residential area $\left(\mathrm{m}^{2}\right)$ & 2.14 & 0.35 & 1.50 & 3.33 \\
\hline & LN_PARKIN & No. of parking lots & 2.02 & 0.57 & 1.39 & 4.62 \\
\hline \multirow{4}{*}{$\begin{array}{l}\text { Spatial and locational } \\
\text { features }\end{array}$} & DIS_CBD & Distance to CBD (km) & 8.07 & 2.93 & 1.90 & 12.60 \\
\hline & DIS_CBD2 & Square of distance to CBD & 73.76 & 45.33 & 3.61 & 158.76 \\
\hline & SUB_PASS & Subway accessibility & 0.60 & 0.49 & 0 & 1 \\
\hline & D_UNIV & Distance to university (km) & 2.00 & 1.89 & 0.05 & 6.40 \\
\hline \multirow{2}{*}{$\begin{array}{c}\text { Neighborhood } \\
\text { environmental attributes }\end{array}$} & AMENITY & No. of public amenities & 0.91 & 0.78 & 0 & 2 \\
\hline & D_PARK & Distance to park (m) & 165.98 & 91.35 & 50.00 & 450.00 \\
\hline \multirow{2}{*}{ Socio-demographic factors } & R_YG1HH & Young single household (\%) & 16.06 & 9.01 & 4.71 & 47.73 \\
\hline & POP_DEN & Population density (=no./ha) & 32.09 & 9.53 & 12.68 & 50.76 \\
\hline
\end{tabular}

\section{Results}

To verify whether there was a spatial dependence, Moran's I test was conducted, as presented in Table 5, using monthly housing rent data. The test statistic had high significance, which implies that there was a problem of spatial autocorrelation. It strongly suggested that a conventional OLS model for hedonic price estimation might not be appropriate; therefore, an alternative model should be considered. Lagrange multiplier tests were conducted to identify a better HPM, as Anselin and Rey [31] proposed. Table 5 shows the five Langrage Multiplier (LM) and Robust LM test statistics used to test either the hypothesis of no spatial lag in a dependent variable, or the hypothesis of no spatial autocorrelation in an error term. Only the LM-Lag test statistic was found to be significant at a 5\% significance level, indicating that there was substantial spatial lag in the dependent variable, that is, monthly housing rent. Therefore, a spatial lag model is preferred for estimating a spatial HPM for small urban houses. The result of the spatial HPM was compared with that of the conventional OLS estimation.

The correlation analysis was conducted before the final models were estimated. Table 6 displays the results of the correlation analysis among the variables used in the final models. 
Table 5. Test for spatial dependence.

\begin{tabular}{cccc}
\hline & MI/DF & $z$-Value & $p$-Value \\
\hline Moran's I (error) & 0.0514 & 3.475 & 0.001 \\
\hline Lagrange Multiplier (lag) & 1 & 5.765 & 0.016 \\
\hline Robust LM (lag) & 1 & 3.793 & 0.051 \\
\hline Lagrange Multiplier (error) & 1 & 2.561 & 0.110 \\
\hline Robust LM (error) & 1 & 0.588 & 0.443 \\
\hline Lagrange Multiplier (SARMA) & 2 & 6.354 & 0.042 \\
\hline
\end{tabular}

Note: The distance threshold of the spatial weight matrix for Moran's I is $700 \mathrm{~m}$.

Table 6. Correlation analysis result.

\begin{tabular}{|c|c|c|c|c|c|c|c|c|c|c|}
\hline & LN_RENT & LN_AREA_RE & LN_PARKING & DIS_CBD & SUB_PASS & D_UNIV & AMENITY & D_PARK & R_YG1HH & POP_DEN \\
\hline LN_RENT & 1.00 & & & & & & & & & \\
\hline LN_AREA_RE & $0.44^{* *}$ & 1.00 & & & & & & & & \\
\hline LN_PARKING & -0.06 & $-0.17^{* *}$ & 1.00 & & & & & & & \\
\hline DIS_CBD & -0.11 & $-0.19 * *$ & 0.12 & 1.00 & & & & & & \\
\hline SUB_PASS & $0.22 * *$ & 0.15 * & $-0.19^{* *}$ & $-0.21 * *$ & 1.00 & & & & & \\
\hline D_UNIV & 0.04 & -0.03 & $0.36^{* *}$ & 0.12 & $-0.47^{* *}$ & 1.00 & & & & \\
\hline AMENITY & $0.20 * *$ & $-0.15^{*}$ & 0.09 & $0.45^{* *}$ & $0.28 * *$ & $-0.22 * *$ & 1.00 & & & \\
\hline D_PARK & 0.11 & -0.09 & $-0.16^{*}$ & -0.03 & $0.21 * *$ & $-0.30 * *$ & $0.16^{*}$ & 1.00 & & \\
\hline R_YG1HH & $0.29 * *$ & 0.03 & $-0.30 * *$ & $-0.52 * *$ & $0.20 * *$ & $-0.20 * *$ & 0.03 & $0.46^{* *}$ & 1.00 & \\
\hline POP_DEN & -0.01 & 0.06 & $0.14^{*}$ & $0.41 * *$ & $-0.21 * *$ & 0.12 & -0.06 & $-0.26^{* *}$ & $-0.54^{* *}$ & 1.00 \\
\hline
\end{tabular}

The final outcomes of estimating HPMs, including OLS and SEM results, are presented in Table 7. They seem to reasonably explain variations in the monthly rents of URH units in the SMA. The final OLS and SEM models accounted for about $42.7 \%$ and $44.4 \%$ of the variations of the dependent variable. Both adjusted R square and likelihood ratio tests suggested that the spatial HPM outperformed the OLS model, which is consistent with findings in previous studies. After looking through the variance inflation factor (VIF) of each explanatory variable, we found no evidence of multicollinearity for either HPM.

Table 7. Results of estimating hedonic price models (HPMs). SEM: spatial error model

\begin{tabular}{|c|c|c|c|c|c|c|c|c|c|}
\hline \multirow{4}{*}{ Category } & \multirow{4}{*}{$\begin{array}{l}\text { Variable } \\
\text { Rho }(\rho) \\
\text { CONT }\end{array}$} & \multicolumn{4}{|c|}{ OLS Model } & \multicolumn{4}{|c|}{ SEM } \\
\hline & & \multirow{3}{*}{$\begin{array}{c}\text { Coefficient } \\
5.541\end{array}$} & \multirow{3}{*}{$\begin{array}{c}\text { Std. Error } \\
0.213\end{array}$} & \multicolumn{2}{|c|}{$t$-Statistics } & \multirow{2}{*}{$\begin{array}{c}\text { Coefficient } \\
0.238\end{array}$} & \multirow{2}{*}{$\begin{array}{c}\text { Std. Error } \\
0.095\end{array}$} & \multicolumn{2}{|c|}{$z$-Value } \\
\hline & & & & & & & & 2.499 & ** \\
\hline & & & & 26.038 & $* * *$ & 4.016 & 0.633 & 6.349 & $* * *$ \\
\hline Housing & LN_AREA_RE & 0.299 & 0.040 & 7.376 & $* * *$ & 0.285 & 0.040 & 7.139 & $* * *$ \\
\hline structures & LN_PARKING & -0.021 & 0.028 & -0.725 & & -0.006 & 0.028 & -0.218 & \\
\hline \multirow{4}{*}{$\begin{array}{c}\text { Spatial and } \\
\text { locational } \\
\text { features }\end{array}$} & DIS_CBD & -0.098 & 0.031 & -3.157 & $* * *$ & -0.061 & 0.032 & -1.894 & * \\
\hline & DIS_CBD2 & 0.006 & 0.002 & 3.074 & $* * *$ & 0.004 & 0.002 & 1.891 & * \\
\hline & SUB_PASS & 0.084 & 0.033 & 2.509 & $* *$ & 0.068 & 0.033 & 2.077 & $* *$ \\
\hline & D_UNIV & 0.043 & 0.009 & 4.733 & $* * *$ & 0.032 & 0.009 & 3.426 & $* * *$ \\
\hline \multirow{2}{*}{$\begin{array}{l}\text { Neighborhood } \\
\text { environmental } \\
\text { attributes }\end{array}$} & AMENITY & 0.065 & 0.026 & 2.478 & $* *$ & 0.053 & 0.026 & 2.028 & $* *$ \\
\hline & D_PARK & 0.000 & 0.000 & 0.845 & & $\begin{array}{c}1.61 \times \\
10^{-4}\end{array}$ & $1.7 \times 10^{-4}$ & 0.946 & \\
\hline \multirow[b]{2}{*}{$\begin{array}{l}\text { Socio-demographic } \\
\text { factors }\end{array}$} & R_YG1HH & 0.008 & 0.002 & 3.506 & $* * *$ & 0.007 & 0.002 & 2.894 & $* * *$ \\
\hline & D_PARK & 0.000 & 0.000 & 0.845 & & $\begin{array}{c}1.61 \times \\
10^{-4}\end{array}$ & $1.7 \times 10^{-4}$ & 0.946 & \\
\hline \multicolumn{2}{|c|}{$\mathrm{R}^{2}$, adj. $\mathrm{R}^{2}$} & \multicolumn{3}{|c|}{$0.427,0.403$} & & \multicolumn{4}{|c|}{$0.444,0.417$} \\
\hline \multirow{2}{*}{\multicolumn{2}{|c|}{ Akaike Information Criterion (AIC) }} & \multicolumn{3}{|c|}{-76.429} & & \multicolumn{4}{|c|}{-79.723} \\
\hline & & \multicolumn{3}{|c|}{12.194} & & \multicolumn{4}{|c|}{12.699} \\
\hline \multicolumn{2}{|c|}{ Koenker-Bassett test } & \multicolumn{3}{|c|}{16.094 * } & & & & & \\
\hline Log-likel & ihood & \multicolumn{3}{|c|}{49.215} & & \multicolumn{4}{|c|}{51.86} \\
\hline \multicolumn{2}{|c|}{ Likelihood ratio test } & & & & & \multicolumn{4}{|c|}{$15.293 * *$} \\
\hline \multicolumn{2}{|c|}{$\mathrm{N}$} & \multicolumn{4}{|c|}{244} & \multicolumn{4}{|c|}{244} \\
\hline
\end{tabular}


When compared with the coefficients of the explanatory variables of the OLS model, the absolute values of the equivalent of the spatial HPM were on the decline. Rho $(\rho)$ as a spatial multiplier revealed the indirect or external effects of spatial interaction among the monthly housing rents on each other. This could be described as the spatial spillover effect, which suggested that the monthly rents of the URH units were positively influenced by those of the adjacent houses at an average of $23.8 \%$ in the SMA, when other variables were controlled.

The results of the SEM indicated that the rents of small urban houses were positively correlated with residential areas. An average of a $0.29 \%$ increase in housing rent would be observed if the size of a house were increased by $1 \%$, all else being equal. The elasticity of the rent with respect to residential areas was higher than that of other housing types, compared with the results of other studies [12]. This suggests that URH rents are much more sensitive to a change of residential areas. However, it is not significantly associated with the number of parking lots. Parking lots had no effect on the rents, because the URH units are likely to be in locations with relatively better access to public transportation. Some of the structural variables that were produced in the measurement step are not included in the final results. The number of bedrooms is excluded, since most of the houses were studio apartments without separate bedrooms, which was correlated with residential areas. In addition, building age was not incorporated, because the buildings were newly constructed as of the end of 2012.

All of the explanatory variables for both spatial and locational attributes were shown to be statistically significant. The distance to the CBD had a negative impact, but on the other hand, the square of the distance to the CBD had a positive influence on housing rents at a $10 \%$ significance level. This suggests that the distance to the CBD has a diminishing marginal impact on housing rents.

Subway accessibility had a positive effect on housing rents, suggesting that a tenant would pay rent higher by $0.07 \%$ on a monthly basis if he or she wanted to live in a house in a TOD ceteris paribus. In addition, the distance to the nearest university was positively correlated with housing rents, implying that the rents of a small urban house tended to be lower if it was located near a university. On average, there was a $0.06 \%$ increase in monthly rents as the distance from an adjacent university increased by $1 \%$, other factors being constant. This seems contrary to the results of previous studies, because most studies conclude that longer distances to elementary, middle, and high schools have a negative influence on house prices.

Both neighborhood environmental variables were found to have significant positive impacts on housing rents. The number of public amenities was positively correlated with housing rents, which confirmed that the monthly rent is expected to rise by $0.05 \%$ if the number of cultural and recreational facilities increase in number within a one-kilometer boundary, all else being equal. Interestingly, the relative distance to the nearest park had no significant effect on rent, which is not consistent with the results of earlier research on hedonic price valuation. This is apparently attributable to the distinct characteristics of young one and two-person households in Seoul.

Socio-demographic factors also positively affected housing rents. Population density in the surrounding residential property had a positive effect on housing rents, suggesting that a $0.11 \%$ rental premium would be charged as the population density around the house increased by $1 \%$. In addition, a positive coefficient of the proportion of young single households meant that for each rent increase of about $0.11 \%, 1 \%$ more young single households would be around the property. Both population density and the proportion of young single households had positive impacts on the rents, because they represent the potential demand for small urban houses.

\section{Conclusions}

This study was mainly concerned with analyzing the effects of locational and neighborhood environmental attributes on the rents of small urban houses using the spatial HPM. A survey was designed to collect information on house prices and the living conditions of households in URH. A variety of locational and neighborhood environments were also measured using GIS techniques. 
With the data that we gathered, we estimated and compared conventional and spatial HPMs. The major findings and implications of this study are summarized follows.

First, a significant spatial dependence was found among the rents charged for URH units. This implies that a conventional HPM based on OLS estimation might be inappropriate. The spatial HPM used to address the spatial dependence problem outperformed the conventional HPM in terms of goodness-of-fit measures. The coefficient estimates of the spatial HPM were all smaller than those of the conventional HPM, indicating that the effects of various attributes would be overestimated in the conventional HPM. In addition, the spatial HPM revealed that the rents of URH units had a positive impact on those of adjacent units. This suggests that, on average, about a quarter of the rents charged for a house were affected by the rents charged in neighboring URH dwellings, and only about three-quarters of the rents could be explained by other factors in the spatial HPM.

Second, the net floor area had a positive effect on the rents of small urban houses, which is consistent with the result of previous studies. However, the number of parking spaces had no significant correlation with the rents, implying that residents are not very interested in the parking spaces on the property. This is due to lower car ownership rates, and more reliance on public transit and non-motorized modes of travel. Based on this result, we cautiously conclude that it might be appropriate to retain the current parking requirement resulting from deregulation by the Housing Act. The parking requirement was relaxed only for studio-type URH dwellings, and this deregulation has helped local developers gain economic feasibility from small urban housing projects. While the parking deregulation encourages developers to build small urban houses, it might yield negative impacts on residential environments due to the shortage of parking space.

Third, all of the locational features, including the distance to the CBD, subway accessibility, and distance to a university were found to be significant. Consistent with the results of related research, subway accessibility was positively associated with the housing rents, which indicates that residents are willing to pay more if they can live in houses with better access to transit. Although not considered in other studies, access to university has a substantial positive effect on the rents of URH units. This is interesting, because rents tended to be lower in areas adjacent to a university, which suggests that this would be a good place for households in terms of enhancing their residential affordability. In terms of housing policy, affordability seems to be more important than accessibility for one and two-person households in the SMA. They sought affordable small urban dwellings because of the excessive housing cost burden in the SMA [3]. It is necessary to establish effective housing policies for them in order to resolve housing affordability issues.

Last, most of the variables that related to the neighborhood environment had significant effects on the rents of small urban houses. The more chances residents had to enjoy public amenities, the higher the premium they were willing to place on the houses. On the other hand, access to parks had no meaningful impact on the rents, which is not consistent with arguments made in previous studies. This is mainly due to the characteristics of those residing in one and two-person households in the SMA. They are inclined to place a premium on mobility and indoor activities, because most of them are quite busy in the daytime, and prefer not to be outdoors in the SMA during the night-time for both safety reasons and their own behavioral reasons. This outcome can be observed in many metropolitan areas with high population densities such as Hong Kong [7]. These households are willing to sacrifice activities in open spaces for the sake of mobility and convenience. It is necessary to consider their preference for amenities in establishing and implementing housing policies in the metropolitan area.

This study contributes to expanding our understanding of the effects of locational and neighborhood environmental attributes on the rents of small urban houses in the SMA. Households living in small urban houses are inclined to place a premium on rents in different ways. The study's outcomes will be useful for academics, policymakers, and real estate practitioners. Our spatial HPM overcomes the weakness of conventional HPM in terms of its explanatory power, while employing diverse explanatory variables. 
Although this study led to meaningful findings, several limitations should be properly addressed in further research. First, the URH information used in this paper needs to be updated, and the number of observations should be expanded. Second, due to the lack of data, explanatory variables used in the literature are not considered in our final results. In particular, environmental factors such as water, views, and noise levels need to be further examined in terms of their impacts on house prices. Third, more sophisticated methods of analysis such as difference-in-difference specification can be employed in future studies. The method can help examine the impacts of locational and environmental attributes in a more rigorous manner by constructing a panel data set [36]. Last, this study focused only on small urban houses located in the SMA. By incorporating data from other metropolitan areas around the world, the arguments used in this study could be generalized for residents living in small urban houses.

Acknowledgments: This study was supported by 2014 Research Grant from Kangwon National University.

Author Contributions: JW and JSL made substantial contributions to conception and design, data analysis, and interpretation of data; participated in drafting the manuscript and revising it critically for important intellectual content; gave final approval of the version to be submitted and published. JSL also made substantial contributions to acquisition of data.

Conflicts of Interest: The authors declare no conflict of interest.

\section{References}

1. Seoul Metropolitan Government (SMG). Seoul Statistical Yearbook; SMG: Seoul, Korea, 2015. Available online: http:/ / stat.seoul.go.kr/jsp3/stat.book.jsp?link=1\&cot=052 (accessed on 15 October 2017).

2. Seoul Metropolitan Government (SMG). Seoul Statistical Yearbook; SMG: Seoul, Korea, 1990. Available online: http:/ / stat.seoul.go.kr/jsp3/stat.book.jsp?link=1\&cot=052 (accessed on 15 October 2017).

3. Lee, J.S.; Seong, S.Y. Development characteristics and supply effect evaluation of Urban-type housing in Seoul. J. Korea Plan. Assoc. 2013, 48, 305-317.

4. Kim, H.J. An Analysis on the Determinants Affecting the Price for Urban-Life Housing Using the Hedonic Price Models. Ph.D. Thesis, Hanyang University, Seoul, Korea, 2012.

5. Lee, D.H.; Lim, M.H.; Ko, S.C. A Study on the factors affecting the rent of urban life housing in Seoul by quantile regression. J. Korean Reg. Dev. Assoc. 2015, 27, 143-164. [CrossRef]

6. Cohen, J.P.; Coughlin, C.C. Spatial hedonic models of airport noise, proximity, and housing prices. J. Reg. Sci. 2008, 48, 859-878. [CrossRef]

7. Hui, E.C.; Chau, C.K.; Pun, L.; Law, M.Y. Measuring the neighboring and environmental effects on residential property value: Using spatial weighting matrix. Build. Environ. 2007, 42, 2333-2343. [CrossRef]

8. Lee, J.S.; Li, M.H. The impact of detention basin design on residential property value: Case studies using GIS in the hedonic price modeling. Landsc. Urban Plan. 2009, 89, 7-16. [CrossRef]

9. Koschinsky, J.; Lozano-Gracia, N.; Piras, G. The welfare benefit of a home's location: An empirical comparison of spatial and non-spatial model estimates. J. Geogr. Syst. 2012, 14, 319-356. [CrossRef]

10. Jayantha, W.M.; Lam, T.I.; Chong, M.L. The impact of anticipated transport improvement on property prices: A case study in Hong Kong. Habitat Int. 2015, 49, 148-156. [CrossRef]

11. Chen, W.Y.; Li, X. Cumulative impacts of polluted urban streams on property values: A 3-D spatial hedonic model at the micro-neighborhood level. Landsc. Urban Plan. 2017, 162, 1-12. [CrossRef]

12. Jun, M.J.; Kim, H.J. Measuring the effect of greenbelt proximity on apartment rents in Seoul. Cities 2017, 62, 10-22. [CrossRef]

13. Krause, A.L.; Bitter, C. Spatial econometrics, land values and sustainability: Trends in real estate valuation research. Cities 2012, 29, 19-25. [CrossRef]

14. Nicholls, S.; Crompton, J.L. The impact of greenways on property values: Evidence from Austin, Texas. J. Leis. Res. 2005, 37, 321-341.

15. Visser, P.; Van Dam, F.; Hooimeijer, P. Residential environment and spatial variation in house prices in the Netherlands. Tijdschr. Econ. Soc. Geogr. 2008, 99, 348-360. [CrossRef]

16. Gibbons, S.; Mourato, S.; Resende, G.M. The amenity value of English nature: A hedonic price approach. Environ. Resour. Econ. 2014, 57, 175-196. [CrossRef] 
17. Tse, R.Y. Estimating neighbourhood effects in house prices: Towards a new hedonic model approach. Urban Stud. 2002, 39, 1165-1180. [CrossRef]

18. Ki, C.O.; Jayantha, W.M. The effects of urban redevelopment on neighbourhood housing prices. Int. J. Urban Sci. 2010, 14, 276-294. [CrossRef]

19. Bolitzer, B.; Netusil, N.R. The impact of open spaces on property values in Portland, Oregon. J. Environ. Manag. 2000, 59, 185-193. [CrossRef]

20. Asabere, P.K.; Huffman, F.E. The relative impacts of trails and greenbelts on home price. J. Real Estate Financ. Econ. 2009, 38, 408-419. [CrossRef]

21. Kuethe, T.H. Spatial fragmentation and the value of residential housing. Land Econ. 2012, 88, 16-27. [CrossRef]

22. Tomkins, J.; Topham, N.; Twomey, J.; Ward, R. Noise versus access: The impact of an airport in an urban property market. Urban Stud. 1998, 35, 243-258. [CrossRef]

23. Espey, M.; Lopez, Z. The impact of airport noise and proximity on residential property values. Growth Chang. 2000, 31, 408-419. [CrossRef]

24. Park, H.M. An analysis of the factors affecting on the price of the Urban-life housing type of the structure of the urban spaces in Seoul. J. Korea Plan. Assoc. 2013, 48, 419-435.

25. Kong, F.; Yin, H.; Nakagoshi, N. Using GIS and landscape metrics in the hedonic price modeling of the amenity value of urban green space: A case study in Jinan City, China. Landsc. Urban Plan. 2007, 79, $240-252$. [CrossRef]

26. Geoghegan, J. The value of open spaces in residential land use. Land Use Policy 2002, 19, 91-98. [CrossRef]

27. Irwin, E.G. The effects of open space on residential property values. Land Econ. 2002, 78, 465-480. [CrossRef]

28. Anselin, L.; Bera, A.K. Spatial dependence in linear regression models with an introduction to spatial econometrics. Stat. Textb. Monogr. 1998, 155, 237-290.

29. Anselin, L. Exploring spatial data with GeoDaTM: A workbook. Urbana 2004, 51, 309-535.

30. Anselin, L. Spatial Econometrics: Methods and Models; Springer Science \& Business Media: Dordrecht, The Netherlands, 2013; Volume 4, ISBN 978-90-481-8311-1.

31. Anselin, L.; Rey, S.J. Modern Spatial Econometrics in Practice: A Guide to GeoDa, GeoDaSpace and PySAL; GeoDa Press LLC: Chicago, IL, USA, 2014.

32. Seoul Metropolitan Government (SMG). Seoul Statistical Yearbook; SMG: Seoul, Korea, 1995. Available online: http:/ / stat.seoul.go.kr/jsp3/stat.book.jsp?link=1\&cot=052 (accessed on 15 October 2017).

33. Seoul Metropolitan Government (SMG). Seoul Statistical Yearbook; SMG: Seoul, Korea, 2000. Available online: http:/ / stat.seoul.go.kr/jsp3/stat.book.jsp?link=1\&cot=052 (accessed on 15 October 2017).

34. Seoul Metropolitan Government (SMG). Seoul Statistical Yearbook; SMG: Seoul, Korea, 2005. Available online: http:/ / stat.seoul.go.kr/jsp3/stat.book.jsp?link=1\&cot=052 (accessed on 15 October 2017).

35. Seoul Metropolitan Government (SMG). Seoul Statistical Yearbook; SMG: Seoul, Korea, 2010. Available online: http:/ / stat.seoul.go.kr/jsp3/stat.book.jsp?link=1\&cot=052 (accessed on 15 October 2017).

36. Bertrand, M.; Duflo, E.; Mullainathan, S. How much should we trust differences-in-differences estimates? Q. J. Econ. 2004, 119, 249-275. [CrossRef]

(C) 2017 by the authors. Licensee MDPI, Basel, Switzerland. This article is an open access article distributed under the terms and conditions of the Creative Commons Attribution (CC BY) license (http://creativecommons.org/licenses/by/4.0/). 